\title{
TEOORIA JA PRAKTIKA VAHEL EHK IKKA PUUDUVAST TÕLKEKRIITIKAST
}

Mõne aja eest ilmus Sirbis Heli Alliku ülevaatlik, lahenduste otsimisele suunatud artikkel tõlkekriitika kidumise ja kadumise põhjustest. ${ }^{1}$ Olulisematena olid nimetatud sobiva väljaande puudumine ning tõlkekriitika kui töö- ja ajamahuka tegevuse väärika hindamise ja tasustamise kehvapoolne seis. Need on nn välised põhjused, millele hea tahtmise korral on võimalik leida enamvähem toimiv lahendus, nagu näiteks artiklis nimetatud blogi või veebiväljaanne. Aga on ka sisemised põhjused, millest Allik teeb põgusamalt juttu ja mis kõige välise taustal võivad rohkemgi takistada tõlkekriitika laiemat praktiseerimist. Olulisematena tõusevad esile kolm aspekti: ,ise õpetame, ise uurime, ise tõlgime ja ise kritiseerime" ehk väike ring tegijaid, kes peavad omavahel sõbralikult läbi saama (Heli Allik toob selle kirjeldamiseks ära PilleRiin Larmi ja Joosep Susi arvamuse, et „kolleegi tööd pole tõlkijate intiimses klannis paslik avalikult kritiseerida"2); teiseks umbusk tõlketeooria suhtes, millest natuke pikemalt allpool, ja kolmandaks kultuuriline alalhoidlikkus. Heli Allik tsiteerib Vikerkaare tõlkearvustusi analüüsinud Maarja Läänesaare tabavat tähelepanekut: „Olukorras, kus suurem osa kirjandusest on tegelikult kellegi väikeste nähtamatute käte tõlge, peab optimismi säilitamiseks olema kultuuril kõvasti usku tõlgitavusse. Meie kultuur on rajatud tõlgitavusele ning süsteemi jaoks on

${ }^{1} \mathrm{H}$. Allik, „Kus aga oht on, seal kasvab ka rohi ta vastu." - Sirp 29. IX 2017.

${ }^{2}$ P-R. Larm, J. Su si, Me kiretu kirjanduskriitika. 2015. ja 2016. aasta kirjanduskriitika ülevaade. - Keel ja Kirjandus 2017, nr 3, lk 178. kindlasti oluline, et selle kultuuri tõlgitust ja võimalikke nuripeegeldusi liiga tõsiselt vaatluse alla ei võetaks [---..”3

Tõepoolest, eesti kultuur on tõlkekultuur ning tõlkimine aina seotud olnud eesti keele ja kirjanduse arendamise ja alalhoidmise, valgustamise ja harimisega, suurte isiksuste ja missiooniga. Sellele põhimõttele on olnud rajatud ka tõlgitavate teoste valik, ${ }^{4}$ tõlked peavad täitma tühikuid. N-ö augutäitematerjal peab aga olema ümbrusega sama tooni, muidu torkab erinevus liialt silma ja aukude suurus saab kõigile nähtavaks nagu keisri uued rõivad. See omakorda tingib teatava „endastmõistetava” tõlkenormi kehtestumise, mis võimaldaks tõlgetel sulanduda, olla nagu „omakeelne tekst” või rohkemgi. ${ }^{5}$ Aastakümnete jooksul on välja kooli-

${ }^{3}$ M. Läänesaar, Tõlkija nähtamatusest tõlkekriitikas. Toimetajast rääkimata. - Sirp 19. III 2010.

4 „Ühesõnaga, me peame püüdma tõlkida võimalikult erinevat kirjandust, mitte niisugust, mille sarnast meil endal on olemas. Väga oluline on ka põhimõte, et peame tõlkima ainult enda jaoks, oma kirjanduse seisust lähtudes. Ainult siis saame anda väärtuslikku tõlkekirjandust. [---] Ta realiseerib ainult neid keeles peituvaid võimalusi, mida ükski eesti kirjanduse teos mitte kunagi ei realiseeriks. Rahuldab ainult neid vajadusi, mis muidu jääksid rahuldamata." (O. Oj a m a a, Kümnenda muusa muresid I. - O. Ojamaa, Armastus seaduslikus abielus. (Eesti mõttelugu 92.) Tartu: Ilmamaa, 2010, lk 62-63.)

5 Tõlkenormid, nagu muudki teksti- ja kultuurinormid ei ole muidugi midagi eesti kultuurile ainuomast, vaid tõlkeuuringutes laialt käsitletud nähtus: „Ajaloolised uurimused näitavad, et ka kõige teooriavaesematel aegadel võib täheldada tõlkeprintsiipide väga suurt ühtsust. Igasugust tõlkemeetodit iseloomustavasse väljajäetu-muudetu-säilitatu vahekorda suhtutakse hinnangulises 
tatud lugejad, kelle ootused tõlketekstile rajanevad illusioonil, et tunnustatud tõlkija toob ise nähtamatuks jäädes teksti ühest kultuurist ja keelest teise ning sellest saab „meie oma”. ${ }^{6}$

Siit on paslik edasi minna teooriaprobleemi juurde ja küsida, kas seegi ei lähtu osaliselt samast allikast, see tähendab, kas mitte teatav väikekultuuri konventsioonidest tingitud kaitsetahe ei põhjusta umbusku tõlkeuuringute suhtes (ja ka tõlketeooria kui millegi suhtes, millel on oht kuidagiviisi tõlkimise praktikaga suhestuda), sest see võiks nähtavale tuua võõraste teoste omakultuuri toomises soositud normid ja toimimisviisid. Tegelikult tuleks muidugi rõhutada, et tõlkeala praktikute ja teoreetikute vähene teineteisemõistmine pole kaugeltki mitte spetsiifiline eesti kultuuri probleem, mitmed nimekad tõlketeoreetikud-uurijad on seda teemat käsitlenud ja jõudnud lausa sellise pessimistliku järelduseni: „On ilmselt väga vähe ameteid, milles valitseb selline haigutav kuristik teooria ja praktika vahel."

\section{Teooria pilvedes, tõlkimine maa peal}

Niisiis väljendavad tõlkijad ikka ja jälle seisukohti, milles teooriat peetakse kasutuks, halvemal juhul aga lausa vaenlaseks. Miks on ilmsem või varjatum teooriavastasus tõlkijate seas nii levinud, kas tegu on üleoleku, ohu-

plaanis konkreetse perioodi raames üheselt ja väga erinevalt eri aegade lõikes. Seega on oma kirjutamata seadused tõlketegevust alati mõjutanud." (P. Torop, R. Sepp, Tõlkimise teooriast ja praktikast. - Sirp ja Vasar 16. I 1981, lk 6.) Sama kehtib ka tõlketegevuse rahvusliku suunitluse kohta.

${ }^{6}$ Vt ka K. Kaldjärv, Tõlkija kui nähtamatu maag: näiteid hispaaniakeelse kirjanduse tõlgetest Jüri Talveti tõlkemõtte valguses. - Methis. Studia humaniora Estonica 2017, nr 17/18, lk 70-93.

7 A. Chesterman, E. Wagner, Can Theory Help Translators: A Dialogue Between the Ivory Tower and the Wordface. Manchester, UK: St Jerome, 2004, lk 1. tunde või teadmatusega? Kas teooriat tajutakse mingi eriliselt süstemaatilise kriitikana, mis toob tõlkijate tegevuse juures välja tahud, millele tõlkijad tavapäraselt mõtlema ei ole harjunud? Peamiseks etteheiteks teooriale (eelkõige praktikute vaatepunktist) näib olevat väide, et praktilisel tõlkimisel, tegelikul tõlketööl ei ole teooriast midagi kasu, see ei aita vahendajat, ei tee tõlget paremaks. ${ }^{8}$ Tõlkimine saab teoks tänu sisetundele ja kogemusele, sügavam järelemõtlemine oma töö üle võib tõlkijat eksitada: „Tõlkimine on suuremalt jaolt intuitiivne, raskesti reeglistatav oskus, mida annab süvendada kogemuse ja lugemusega, töö ja vaevaga, võrdlemise ja tagasisidega. Kas ka tõlketeadusega? Eriti vist mitte. Oma töö üle reflekteerimiseks piisab tõlkijale enamasti kooligrammatika kategooriatest, peenemad tööriistad - tõlkesemiootika jms - on juba ülearused." " Professionaal teab, et tõlkimine on eraklik, individuaalne, konkreetne, praktiline ja vahetu tegevus. ${ }^{10}$ Sagedane paistab olevat väide, et iga probleem, tekst või tõlge on erinev, üldistused ja seega korduvalt kasuta-

\footnotetext{
${ }^{8}$ Rääkides sellest, kui kasutu ja ülearune on tõlketeooria, ei määratle praktikud tavaliselt seda, mida nad täpsemalt silmas peavad, mille suhtes vastumeelsust ja umbusku väljendavad. Tõlketeooria või -uuringud sisaldavad mitmeid erinevaid suundi ja koolkondi, mis ei ole omavahelistest vastuoludest vabad. Kui mõelda James Holmes'i 1972. aastal ilmunud artiklis „The name and nature of translation studies" visandatud tõlkeuuringute peamistele harudele - rakenduslikule, kirjeldavale ja teoreetilisele -, siis võivad tõlkeuurijad pakkuda lahendusvõimalusi konkreetsetele probleemidele, arutleda keerukate mudelite abil tõlkefilosoofia üle, rääkida tõlke ajaloost mingis keeleruumis, kirjeldada tõlke retseptsiooni ja tõlkija positsiooni ühiskonnas, uurida tõlkimist kui kognitiivset protsessi jne.

${ }^{9} \mathrm{M}$. Väljataga, Tõlkimise teooriast ja praktikast. - Sirp 27. XI 2008.

${ }^{10}$ Kuus küsimust Eesti Kultuurkapitali 2013. aasta tõlkekirjanduse auhinna nominentidele. Küsitles Heli Allik. - Tõlkija hääl II. Eesti Kirjanike Liidu tõlkijate sektsiooni aastaraamat. Tallinn: SA Kultuurileht, 2014, lk 49-67.
} 
tavad strateegiad välistatud. Ka olevat tõlketeooria mõistestik nii keeruline, esoteeriline ja praktikakauge, et tõlkijad ei ole võimelised seda oma töös kasutama. ${ }^{11}$ Tõlkest rääkimine on keeruline, kui mitte võimatu, ja kõikvõimalikud teooriad võivad pilti ainult ähmastada: „Tõlkimise käsitlemise ajavad sogasemaks ekstravagantsed teooriad, mille järgi polevat üldse võimalik sama asja teiste sõnadega, ammugi siis mitte teiskeelsete sõnadega ümber ütelda."12 Tõlketeooriale võib ette heita kaugenemist tõlkimise igapäevasest tegelikkusest, tegelemist omaenese loodud abstraktsioonidega: „Ka siin nähtub uusimatel aegadel teoreetilise abstraktsiooni hüppeline eemaldumine tõlkimise ja tõlke reaalsest ajaloolisest praktikast, sulgumine enesekaemuse labürinti. Tõlkimise kui fundamentaalse kultuuriteguri selgitamist tundub asendavat teadlik objekti hämardamine, müstifitseerimine, hajutamine, laialikiskumine." ${ }^{33}$

Oma arvamuse väljaütlemisel ei pea kõige teenekamad tõlkijad ja kirjanikud mahendavaid pooltoone kasutama: „Ma ei usu mingi vähegi produktiivse tõlketeooria olemasolusse. [---] Tõlkida tuleb hästi, tõlkida tuleb õigesti, tõlkida tuleb adekvaatselt, tõlkida tuleb nii, et tõlget lugedes tundub, et loetakse originaali." ${ }^{14}$ Teooriate pelutavusest ja nende pidurdamatust pealetungist rääkides tuleb paiguti appi võtta tõrjemaagilised võõrsõnad: „Juba raamatukogusid moodustavate tõlketeoreetiliste kompendiumide kohta võtan endale läbinisti subjektiivse vabaduse ja vastutuse öelda:

11 J-P. Mailhac, Formulating strategies for the translator. - Translation Journal 2007, nr 11/2. http://translationjournal.net/ journal/40strategies.htm (16. XI 2017).

${ }^{12} \mathrm{M}$. Väljat a ga, Tõlkimise teooriast ja praktikast.

13 J. Talvet, Mõtteid tänapäeva tõlkefilosoofiast. Kas antropofaagia või sümbioos? - Keel ja Kirjandus 2006, nr 5, lk 354.

14 J. Kross, Tõlkimine - kas kunst? kas teooria? - J. Kross, Omaeluloolisus ja alltekst. 1998. a. Tartu Ülikooli filosoofiateaduskonna vabade kunstide professorina peetud loengud. Tallinn: Eesti Keele Sihtasutus, 2003, lk 210. horribilis!"15 Tõlkijal on igati põhjust olla teooria suhtes üleolev: „Samal põhjusel paneb ka tõlketeaduse nime all viljeldav diskursus elukutselise tõlkija natuke muigama - tõlketöö igapäevaprobleemide kõrval paistab see niivõrd eluvõõras ja tegelikkusekauge - eriti veel siis, kui tõlketeoreetiline traktaat väldib näidete toomist."16

Teoreetikud mängivad klaaspärlimängu, praktikud teevad musta tööd: „tõlketeoorias levivad erinevad interpretatsioonid, iga teadlane laob valmis oma kaardimajakese. Ja miks mitte, minu meelest on see põnev mäng. Aga mis puutub sellesse, et selle teooriaga ei ole konkreetsele tekstile lähenedes midagi pihta hakata, siis see on ju samuti loomulik.”" „Kõrgel üldistustasemel, nagu filosoofid või tõlketeoreetikud tõlkimist ja tõlgendamist käsitlevad, jääb nende käsitluste seos konkreetse tõlkejuhuga kaugeks. Objektist puhtaks abstraheeritud üldistused võivad elada omasoodu abstraktsioonide taevas, praktika käib aga tihtipeale maadligi oma rada."18

\section{Iga tõlkija on teoreetik}

Läänemaailmas mõistetakse tõlketeooriat paratamatult juba selle sünnist normatiivsena. Alates Cicerost ja Hieronymusest on tõlkijad ja tõlketeoreetikud astunud nende jälgedes, eeldades mitte ainult seda, et tõlge saab olla kas vaba või sõnasõnaline, vaid ka seda, et teooria peab langetama valiku emma-kumma kasuks ja ütlema tõlkijatele, kuidas tõlkida. Viimaste aastakümnete jooksul on seisukoht, et tõlketeooria peaks tõl-

${ }^{15}$ M. Sirkel, Arusaamatus ja arusaam. - Tõlkija hääl II. Eesti Kirjanike Liidu tõlkijate sektsiooni aastaraamat. Tallinn: SA Kultuurileht, 2014, lk 9.

${ }^{16} \mathrm{M}$. Väljataga, Tõlkimise teooriast ja praktikast.

${ }^{17}$ Kuus küsimust Eesti Kultuurkapitali 2013. aasta tõlkekirjanduse auhinna nominentidele, lk 49.

${ }_{18}$ Kuus küsimust Eesti Kultuurkapitali 2013. aasta tõlkekirjanduse auhinna nominentidele, lk 50 . 
kijatele normatiivsed reeglid leiutama, sattunud kriitikatule alla ja paljud teoreetikud on püüdnud tõlkest rääkida mittenormatiivselt, kuid aastasadade vältel juurdunud ettekujutus teooria ja praktika vahekorrast on visa kaduma. Isegi need tõlkijad, kes ei pea teooriast lugu, osutades selle paternalistlikkusele (justkui tõlkijad ei teaks, kuidas oma tööd teha ja peaksid ootama abi teoreetikutelt) ja negatiivsusele (rõhutab peamiselt tõlkijate eksimusi), ootavad preskriptiivsetelt teoreetikutelt abi ja nõuandeid. ${ }^{19}$

Tõlkeuuringutes suure „pöörde” põhjustanud kirjeldav suund ${ }^{20}$ püüdis end ettekirjutuslikust mainest vabastada ja ainult kirjeldada, selgitada ja mõista, mida tõlkijad teevad (milliseid strateegiaid kasutavad nad antud keelelistes ja ühiskondlik-kultuurilistes tingimustes, milliseid norme järgivad, millised väärtused on nende normide taga, millised on tõlkijate tegevuse mõjud lugejatele, kultuuridele ja kultuuridevahelistele suhetele), mitte neid õpetada. ${ }^{21}$ Andrew Chesterman kirjeldab tõlkija ja teoreetiku vahekorda läbi eksiarvamuste, mis teineteise suhtes valitsevad: praktiseeriva tõlkija vaatepunktist näivad teoreetikud olevat kusagil kõrgemal ja nende käsutuses on teadmised, mida nad jagavad all olevatele tõlkijatele, kes ootavad paremini tõlkimise nimel nõuandeid. Enamik tänapäeva tõlkeuurijaid peavad

${ }^{19}$ D. Robin s o n, Normative model. - The Routledge Encyclopedia of Translation Studies. Toim M. Baker, K. Malmkjaer. LondonNew York: Routledge, 2004, lk 161-163.

${ }^{20}$ Kirjeldavad tõlkeuuringud seavad esiplaanile olemasolevad tõlked kui vastuvõtva kultuuri elemendid (erinevalt teistest käsitlustest, mis püüdsid rääkida sellest, mida tõlkija peab tegema, et ideaalse tõlkeni jõuda). Nimi pärineb 1995. aastal ilmunud Gideon Toury raamatust „Descriptive Translation Studies and Beyond", kuid alguse sai suund juba eespool mainitud J. Holmes'i artiklist (vt märkus 8), mis muuhulgas osutas vajadusele käsitleda tõlkeuuringuid iseseisva distsipliinina.

${ }^{21}$ A. Chesterman, The Memes of Translation. Amsterdam: John Benjamins, 1997, lk 48. seda vaatepunkti aga kummaliseks, sest nad üritavad kirjeldada, selgitada ja mõista, mida tõlkijad tegelikult teevad, ja sellest kirjeldavast vaatepunktist nähtuna on just tõlkijad „kõrgel” ja teoreetikud „all”, püüdes aru saada, kuidas tõlkijad küll hakkama saavad. ${ }^{22}$

Tunnistades, et puuduvad kindlad tõendid selle kohta, et teooria aitab tõlkijal paremini tõlkida, loetleb Anthony Pym siiski terve rea tegureid, mis tõlkijale teooriate tundmise puhul kasu võivad tuua. Tõlkealase hariduseta tõlkijad on ehk kiiremad ja efektiivsemad, sest nad teavad vähem keerulistest teooriatest, seetõttu on neil vähem kõhklusi ja nad raiskavad vähem aega endastmõistetavate küsimuste üle juurdlemisele. Teisest küljest võib praktilisest vaatepunktist olla kasulik omada mõningaid teadmisi erinevate teooriate kohta siis, kui on vaja lahendadad probleeme, mille tarvis ei ole olemas kindlaksmääratud lahendusi. Teooriad võivad aidata esitada loomingulisi küsimusi ja vahetevahel anda mitteilmseid vastuseid. Teatud teooriad võivad tõlkijatel aidata parendada oma professionaalset enesekuvandit. ${ }^{23}$ Niisiis näitab teooria meile, et asju võib näha mitmel viisil ja teooria tundmine annab meile võime tavapäraseid lähenemisviise kahtluse alla seada.

Tõlketeooria kohta on ikka küsitud, kas see kannatab välja võrdluse kirjandus- või kunstiteooriaga, kas see on üldse iseseisev. Otto Samma toob 1962. aastal teooria kaitseks kirjutades välja võrdluse kirjandusteooriaga: „Aeg-ajalt on väidetud, et tõlketeooriat polevat üldse vaja. Et ilukirjanduse tõlkimine on kunst, ei saavat ükski teooria kedagi õpetada hästi tõlkima. Tõlke õnnestu-

${ }^{22}$ A. Chesterman, E. Wagner, Can Theory Help Translators: A Dialogue Between the Ivory Tower and the Wordface, lk 2.

${ }^{23}$ A. Py m, Teorías contemporáneas de la traducción. Materiales para un curso universitario. Tarragona: Intercultural Studies Group URV, 2011. http://isg.urv.es/publicity/ isg/publications/2011_teorias/index.htm (16. XI 2017). 
mine või ebaõnnestumine olenevat tõlkija talendist - milleks siis teooria? // Sellele võib vastu väita, et ka kirjandusteooria (mille vajalikkuses kahtlejaid vaevalt leidub) pole ju kedagi suutnud kirjanikuks õpetada, kui inimesel endal annet ega kutsumust ei ole. Ometi võib kirjandusteooria kirjanduse arenemiskäiku suunata, selgitada, mis on hea ja mis on halb; ja küllap on kirjanikud ka kirjandusteadusest ning kriitikast ühtteist kasulikku saanud." ${ }^{24}$

Kui Sammaga nõustuda ja paralleelsusega jätkata, siis võime küsida, mis saaks kirjanduskriitikast ja raamatu-

24 O. Samma, Üht-teist tõlkimisest ja tõlkijatest. - Keel ja Kirjandus, 1962, nr 7, lk 390 . arvustustest, kui tunnustatud kirjanikud vihjaksid sagedasti kirjandusteooria ülearususele ja kasutusele ning peaksid vajalikuks rõhutada, et kirjanikul sellest mingit kasu ei tõuse. Kui tõlketeooriat, tõlkeuurimust peetakse ebaoluliseks, millekski, mis pole tõlkimisega otseselt seotud, vaid sellel otsekui ballastina küljes ripub, siis ei ole loota ka asjatundlikumat kriitikat, sest puudub tõlkest rääkimise kogemus ja oskus, tõlke üle arutamise võimaluste tundmine. Ja ettekujutus tõlke olemusest ei välju kindlakskujunenud raamidest. 